\title{
On immediate bleeding following polypectomy
}

We thank Papastergiou et al. for their interest in our recently published study. In our meta-analysis [1], a lower rate of overall adverse events (AEs) (immediate/delayed bleeding and perforation) was observed with HSP compared to CSP (20/546 [3.7\%] vs. 36/545 [6.6\%], pooled OR 0.53, $P=0.03)$. The delayed bleeding rates were not statistically different between the two groups whereas the immediate bleeding rate was significantly lower in the HSP group (18/546 [3.3\%]) compared to the CSP group (36/ 545 [6.6], pooled OR 0.48, $P=0.01$ ) allowing the HSP group to have a lower rate of overall AEs compared to the CSP group.

We agree that immediate bleeding is destined to occur after cold snare polypectomy due to lack of coagulation current and in the majority of the situations is a slow, capillary bleeding that spontaneously stops and does not need intervention $[2,3]$. The immediate bleeding did not increase the need for blood transfusion and/or hospital admission in all included trials in our study and was successfully managed with endoscopic hemostasis. However, the potential issue with immediate bleeding is need for treatment (eg hemostatic clips), increasing costs and procedure time as well as obscuring the endoscopist view of the polypectomy site for meticulous inspection. However, the current literature is insufficient to address this in comparison with HSP and the studies included in our analysis reported a general "immediate bleeding rate." We need more prospective research specifically powered to evaluate all AEs and costs between CSP and HSP groups, which will shed light on gauging the true clinical impact of immediate bleeding following CSP.

\section{Competing interests}

None

The authors

Ramprasad Jegadeesan, Prateek Sharma

Department of Gastroenterology and Hepatology, University of Kansas Medical Center, Kansas City, Missouri, United States

Corresponding author

Ramprasad Jegadeesan, MD

University of Kansas medical center -

Gastroenterology and Hepatology, 3901

Rainbow Blvd, Kansas City, Kansas 66160

Fax: +1-913-588-3877

drramprasad18@gmail.com
References

[1] Jegadeesan R, Aziz M, Desai M et al. Hot snare vs. cold snare polypectomy for endoscopic removal of $4-10 \mathrm{~mm}$ colorectal polyps during colonoscopy: a systematic review and meta-analysis of randomized controlled studies. Endosc Int Open 2019; 7: E708-E716

[2] Ichise Y, Horiuchi A, Nakayama Y et al. Prospective randomized comparison of cold snare polypectomy and conventional polypectomy for small colorectal polyps. Digestion 2011; 84: 78 - 81

[3] Paspatis G, Tribonias G, Konstantinidis K et al. A prospective randomized comparison of cold vs hot snare polypectomy in the occurrence of postpolypectomy bleeding in small colonic polyps. Colorectal Dis 2011; 13: e345-e348

\section{Bibliography}

DOI http://dx.doi.org/10.1055/a-0966-8595

Endoscopy International Open 2019; 07: E1033

(c) Georg Thieme Verlag KG

Stuttgart · New York eISSN 2196-9736

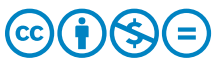

